\title{
Botulinum Toxin Type A for Treatment of Masseter Hypertrophy: Volumetric Analysis of Masseter Muscle Reduction over Time
}

Edward Ilho Lee ${ }^{1}$, Nam-Ho Kim ${ }^{2}$, Ro-Hyuk Park ${ }^{2}$, Jong-Beum Park ${ }^{2}$, Tae Joo Ahn ${ }^{2}$

${ }^{1}$ Division of Plastic Surgery, Baylor College of Medicine, Houston, TX, USA; ${ }^{2}$ Gyalumhan Plastic Aesthetic Clinic, Seoul, Korea
No potential conflict of interest relevant to this article was reported.
Background There has been increasing interest in facial contouring procedures throughout Asian countries. As such, botulinum toxin A injections for masseteric hypertrophy have become a common procedure provided to patients who desire non-surgical correction of a square-angled mandible. We published a retrospective review of our initial results and our technique and treatment protocol in 2005 . We also completed a longterm follow-up of the results (average follow-up period of 4.28 years) and the efficacy of repeated injections in 2010. The purpose of the current study is to systematically evaluate the changes to the masseter muscle at weekly intervals to determine the physiologic effects of botulinum toxin A injection.

Methods Eight patients were prospectively followed on a weekly basis after botulinum toxin A injection for masseteric hypertrophy. Eight patients were followed for 15 weeks and four patients were followed for 25 weeks. Changes in the thickness of the muscle were recorded and analyzed.

Results A reduction in the muscle thickness was found during the clenching phase of the muscle in the first week followed by a reduction in thickness during the resting phase in the second week. The reduction in muscle thickness continued until the eleventh week after which there was a gradual, but incomplete, return of muscle thickness over the study period.

Conclusions There is a predictable, phasic reduction in muscle thickness after botulinum toxin $A$ injection for masseteric hypertrophy. This reduction first occurs during the clenching phase followed by a concomitant reduction during the resting phase. Maximal size reduction occurs at 11 weeks followed by gradual muscle size recovery.

Keywords Botulinum toxins type A, Hypertrophy, Nerve block

\section{INTRODUCTION}

The concept of beauty has long been defined by regional and cultural differences. These differences, however, are changing at a fast

Received: May 23, 2016 Revised: Jun 21, 2016 Accepted: Jun 22, 2016 Correspondence: Tae Joo Ahn Gyalumhan Plastic Surgery, 21st Mijinplaza, 390 Gangnam-daero, Gangnam-gu, Seoul 06232, Korea.

E-mail: cmcanti@hanmail.net

Copyright @ 2016 The Korean Society for Aesthetic Plastic Surgery.

This is an Open Access article distributed under the terms of the Creative Commons Attribution Non-Commercial License (http://creativecommons.org/licenses/by-nc/4.0/) which permits unrestricted non-commercial use, distribution, and reproduction in any medium, provided the original work is properly cited. $\quad w w w . e-a a p s . o r g$ pace to create a homogenization of standards of beauty. In Asian countries, the egg-shaped face of Western people is generally preferred over the square-angled face that is often seen in Asians. As such, there has been increasing interest and demand for facial contouring procedures throughout Asian countries, including masseteric resection and/or mandible angle ostectomy [1]. However, given the length of recovery and the complication profile, efforts have been made to utilize non-surgical modalities for treatment. Since its introduction, botulinum toxin A injection has become an important modality in the treatment of a square-angled jaw [2]. The efficacy and the long-term results are well documented in the literature, including two previous reports from our group $[3,4]$. What is not known, however, is when and how masseter muscle reduc- 
tion occurs. The purpose of this study is to systematically evaluate changes to the masseter muscle at weekly intervals to determine the physiologic effects of the injection during the treatment period.

\section{METHODS}

Eight of the patients with masseteric hypertrophy who presented to our clinic from October of 2012 to July of 2013 desiring botulinum toxin A injection were randomly selected to participate in this study. Prior to injection, ultrasound was used to measure the size (thickness) of the masseter muscle. To standardize our findings, all measurements were taken on the same point on the masseter by the same provider using the same ultrasound equipment. In addition, all injections were given by the same provider using the same injection technique.

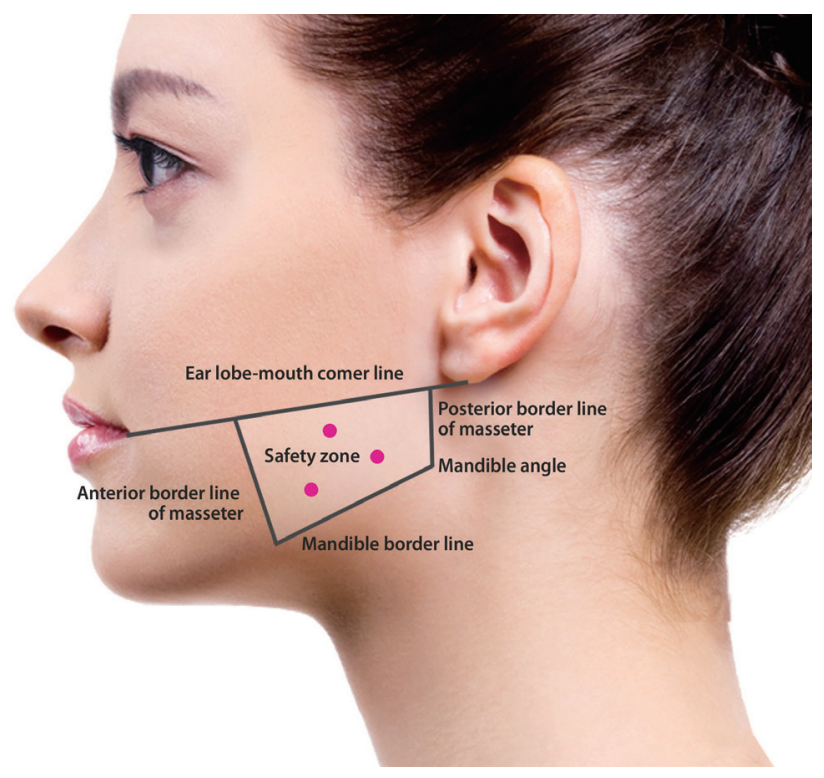

Fig. 1. Reference landmarks for injection. A quadrangular zone is drawn demarcating the area in which the masseter is well-developed and is at a safe distance from vital anatomic structures. Three injection points are selected taking into consideration the diffusion potential of the toxin. [Reprinted from "Aesthetic plastic surgery in Asians: principles and techniques", by Pu LLQ, 2015, p.176. Copyright 2015 by the CRC Press. Reprinted with permission].
In order to measure the thickness of the masseter muscle, the anterior and posterior borders of the masseter were first determined by having the patient clench his or her teeth. Next, the midpoint of the muscle was determined by drawing a line connecting the earlobe to the corner of the mouth, and an ultrasound probe was then placed gently on the skin. Care was taken not to apply too much pressure on the probe as this can compress the muscle and thus reduce the perceived thickness of the muscle.

Each bottle containing 100 units (U) of botulinum toxin A (Botulax $^{\circledR}$, Hugel pharma Co., Ltd, Seoul, Korea) was reconstituted to a final concentration of $40 \mathrm{U}$ per cc in sterile saline. The masseter was injected at three points within a safe zone along the muscle as described in our previous article (Fig. 1) [4]. Depending on the thickness of the masseter muscle, $0.8 \mathrm{cc}(32 \mathrm{U})$ to $1.0 \mathrm{cc}(40 \mathrm{U})$ was injected in each masseter at the initial visit.

Each patient was seen on a weekly basis for 15 consecutive weeks. At each visit, the thickness of each masseter muscle was measured, once with the muscle at rest (resting phase) and again at maximum contraction after asking the patient to clench his or her teeth (clenching phase). Given that the time to the onset of action of botulinum toxin $\mathrm{A}$ is between 2 to 9 days, an additional $0.2 \mathrm{cc}(8 \mathrm{U})$ to $0.3 \mathrm{cc}$ (12 U) was injected at the 2-week visit if there was evidence of residual masseter muscle activity during the clenching phase. Four of the eight patients were followed for an additional 10 weeks (25 total weeks).

Data analysis was performed using SAS software version 9.2 (SAS Institute, Cary, NC, USA). The Wilcoxon singled rank test was used to compare the data (reported as the mean \pm standard deviation, median, and minimum value-maximum value) at each entry point. P-values of less than 0.05 were considered significant.

\section{RESULTS}

All patients enrolled in the study completed either the 15- or 25week treatment protocol. All patients had a reduction in the thickness of the masseter muscle and were satisfied with the results. There were no complications to report throughout the treatment period.

On average, $0.92 \pm 0.08 \mathrm{cc}(36.8 \pm 3.2 \mathrm{U})$ and $0.89 \pm 0.06 \mathrm{cc}(35.6 \pm$ $2.4 \mathrm{U}$ ) of botulinum toxin A was injected to the left and right side, respectively (Table 1). Three of the eight patients required an addi-

Table 1. Dose of follow-up group

\begin{tabular}{|c|c|c|c|c|c|c|c|c|}
\hline \multirow{3}{*}{ Injection } & \multicolumn{8}{|c|}{ Dose } \\
\hline & \multicolumn{4}{|c|}{ Left } & \multicolumn{4}{|c|}{ Right } \\
\hline & $\mathrm{N}$ & Mean \pm SD & Median & Min-Max & $\mathrm{N}$ & Mean \pm SD & Median & Min-Max \\
\hline Baseline & 8 & $36.8 \pm 3.2 \mathrm{U}$ & $37.2 \mathrm{U}$ & $32-40 \mathrm{U}$ & 8 & $35.6 \pm 2.4 \mathrm{U}$ & $36 U$ & $32-38 \mathrm{U}$ \\
\hline 2nd injection & 3 & $10.8 \pm 2.4 U$ & $12 U$ & $8-12 \mathrm{U}$ & 2 & $12 \pm 0.0 \mathrm{U}$ & $12 U$ & $12-12 \mathrm{U}$ \\
\hline
\end{tabular}

U, Unit. 
tional injection at a 2-week follow-up visit with an average of $0.27 \pm$ $0.06 \mathrm{cc}(10.8 \pm 2.4 \mathrm{U})$ and $0.30 \pm 0.00 \mathrm{cc}(12.0 \pm 0.0 \mathrm{U})$ of toxin to the left and right side, respectively.

The baseline thickness of the masseter muscle with clenching and at rest was $15.03 \pm 1.21 \mathrm{~mm}$ and $12.93 \pm 0.66 \mathrm{~mm}$, respectively
(Table 2). At a 15-week follow-up, the muscle thickness with clenching and at rest was $10.69 \pm 1.39 \mathrm{~mm}$ and $9.76 \pm 0.92 \mathrm{~mm}$, respectively, a statistically significant reduction in size from the baseline $(\mathrm{P}<0.05)$. However, at a 25 -week follow-up for 4 of the 8 patients, the muscle size with clenching and at rest was $12.25 \pm 0.86 \mathrm{~mm}$ and

Table 2. Masseter muscle thickness of follow-up group at week 15 and week 25

\begin{tabular}{|c|c|c|c|c|c|c|c|}
\hline \multirow{3}{*}{ Week } & \multirow{3}{*}{$\mathrm{N}$} & \multicolumn{6}{|c|}{ Masseter muscle thickness (mm) } \\
\hline & & \multicolumn{3}{|c|}{ Clenching } & \multicolumn{3}{|c|}{ Resting } \\
\hline & & Mean \pm SD & Median & Min-Max & Mean \pm SD & Median & Min-Max \\
\hline 0 & 8 & $15.03 \pm 1.21$ & 15.33 & $12.35 \sim 15.95$ & $12.93 \pm 0.66$ & 12.90 & $11.95 \sim 13.90$ \\
\hline 15 & 8 & $10.69 \pm 1.39$ & 10.43 & $8.50 \sim 12.35$ & $9.76 \pm 0.92$ & 9.53 & $8.50 \sim 11.25$ \\
\hline 25 & 4 & $12.25 \pm 0.86$ & 12.30 & $11.15 \sim 13.25$ & $10.99 \pm 0.85$ & 10.85 & 10.10 12.15 \\
\hline Change (week15-week0) & & $-4.34 \pm 1.31$ & -4.00 & $-6.30 \sim-2.35$ & $-3.17 \pm 0.62$ & -3.27 & $-4.00 \sim-2.20$ \\
\hline P-value & & \multicolumn{3}{|c|}{$0.0078 *$} & \multicolumn{3}{|c|}{$0.0078 *$} \\
\hline Change (week25-week0) & & $-3.08 \pm 0.64$ & -3.18 & $-3.65 \sim-2.30$ & $-2.01 \pm 0.28$ & -2.00 & $-2.30 \sim-1.75$ \\
\hline P-value & & \multicolumn{3}{|c|}{0.1250} & \multicolumn{3}{|c|}{0.1250} \\
\hline
\end{tabular}

*Statistically significant.

Table 3. Masseter muscle thickness of follow-up group

\begin{tabular}{|c|c|c|c|c|c|c|c|c|c|c|c|}
\hline \multirow{3}{*}{ Week } & \multirow{3}{*}{$\mathrm{N}$} & \multicolumn{9}{|c|}{ Masseter muscle thickness (mm) } & \multirow{3}{*}{ P-value } \\
\hline & & \multicolumn{3}{|c|}{ Clenching } & \multicolumn{3}{|c|}{ Resting } & \multicolumn{3}{|c|}{ Clenching-resting } & \\
\hline & & Mean \pm SD & Median & Min-Max & Mean \pm SD & Median & Min-Max & Mean \pm SD & Median & Min-Max & \\
\hline 0 & 8 & $15.03 \pm 1.21$ & 15.33 & $12.35-15.95$ & $12.93 \pm 0.66$ & 12.90 & $11.95-13.90$ & $2.10 \pm 0.78$ & 2.35 & $0.40-2.80$ & $0.0078 *$ \\
\hline 1 & 8 & $13.24 \pm 0.89$ & 13.05 & $11.51-14.30$ & $12.59 \pm 0.72$ & 12.48 & $11.75-13.75$ & $0.65 \pm 0.46$ & 0.67 & $-0.24-1.20$ & $0.0156 *$ \\
\hline 2 & 8 & $12.14 \pm 1.20$ & 12.18 & $10.30-13.75$ & $11.89 \pm 0.93$ & 12.03 & $10.30-13.00$ & $0.26 \pm 0.33$ & 0.10 & $0.00-0.80$ & $0.0156 *$ \\
\hline 3 & 8 & $11.33 \pm 0.99$ & 11.20 & $10.10-12.80$ & $11.26 \pm 0.92$ & 11.13 & $10.10-12.70$ & $0.07 \pm 0.12$ & 0.02 & $0.00-0.35$ & 0.1250 \\
\hline 4 & 8 & $10.65 \pm 0.88$ & 10.53 & $9.45-12.20$ & $10.56 \pm 0.83$ & 10.40 & $9.45-12.00$ & $0.09 \pm 0.08$ & 0.13 & $0.00-0.20$ & 0.0625 \\
\hline 5 & 8 & $10.52 \pm 0.96$ & 10.50 & $9.30-12.05$ & $10.35 \pm 0.81$ & 10.33 & $9.30-11.50$ & $0.17 \pm 0.19$ & 0.15 & $0.00-0.55$ & 0.0625 \\
\hline 6 & 8 & $10.66 \pm 0.88$ & 10.48 & $9.60-11.90$ & $10.16 \pm 0.69$ & 10.15 & $9.25-11.20$ & $0.49 \pm 0.27$ & 0.53 & $0.00-0.80$ & $0.0156 *$ \\
\hline 7 & 8 & $10.77 \pm 0.85$ & 10.75 & $9.45-11.90$ & $10.09 \pm 0.67$ & 10.00 & $9.20-11.05$ & $0.68 \pm 0.33$ & 0.80 & $0.15-1.00$ & $0.0078 *$ \\
\hline 8 & 8 & $10.61 \pm 0.93$ & 10.53 & $9.20-11.85$ & $9.93 \pm 0.70$ & 9.75 & $9.00-11.05$ & $0.69 \pm 0.34$ & 0.70 & $0.20-1.05$ & $0.0078 *$ \\
\hline 9 & 8 & $10.42 \pm 0.98$ & 10.30 & $8.95-11.90$ & $9.83 \pm 0.69$ & 9.65 & $8.80-10.85$ & $0.59 \pm 0.34$ & 0.60 & $0.15-1.15$ & 0.0078* \\
\hline 10 & 8 & $10.42 \pm 1.20$ & 10.18 & $8.80-12.45$ & $9.75 \pm 0.76$ & 9.58 & $8.75-10.90$ & $0.67 \pm 0.49$ & 0.63 & $0.05-1.55$ & $0.0078 *$ \\
\hline 11 & 8 & $10.35 \pm 1.13$ & 10.08 & $8.85-12.40$ & $9.71 \pm 0.76$ & 9.58 & $8.70-10.90$ & $0.64 \pm 0.42$ & 0.58 & $0.15-1.50$ & $0.0078 *$ \\
\hline 12 & 8 & $10.41 \pm 1.05$ & 10.25 & $8.85-12.25$ & $9.78 \pm 0.75$ & 9.68 & $8.75-11.10$ & $0.64 \pm 0.35$ & 0.60 & $0.10-1.15$ & $0.0078 *$ \\
\hline 13 & 8 & $10.45 \pm 1.11$ & 10.28 & $8.60-12.20$ & $9.79 \pm 0.82$ & 9.60 & $8.60-11.20$ & $0.66 \pm 0.33$ & 0.67 & $0.00-1.00$ & $0.0156 *$ \\
\hline 14 & 8 & $10.48 \pm 1.29$ & 10.23 & $8.45-12.55$ & $9.78 \pm 0.91$ & 9.55 & $8.45-11.30$ & $0.71 \pm 0.42$ & 0.60 & $0.00-1.25$ & $0.0156 *$ \\
\hline 15 & 8 & $10.69 \pm 1.39$ & 10.43 & $8.50-12.35$ & $9.76 \pm 0.92$ & 9.53 & $8.50-11.25$ & $0.92 \pm 0.98$ & 0.60 & $0.00-3.20$ & $0.0156 *$ \\
\hline 16 & 4 & $10.31 \pm 1.46$ & 10.30 & $8.55-12.10$ & $9.73 \pm 1.05$ & 9.75 & $8.45-10.95$ & $0.59 \pm 0.44$ & 0.55 & $0.10-1.15$ & 0.1250 \\
\hline 17 & 4 & $10.36 \pm 1.42$ & 10.35 & $8.65-12.10$ & $9.76 \pm 0.95$ & 9.80 & $8.60-10.85$ & $0.60 \pm 0.50$ & 0.55 & $0.05-1.25$ & 0.1250 \\
\hline 18 & 4 & $10.59 \pm 1.53$ & 10.55 & $8.80-12.45$ & $9.84 \pm 0.99$ & 9.85 & $8.65-11.00$ & $0.75 \pm 0.54$ & 0.70 & $0.15-1.45$ & 0.1250 \\
\hline 19 & 4 & $10.61 \pm 1.46$ & 10.73 & $8.75-12.25$ & $9.81 \pm 0.93$ & 9.88 & $8.65-10.85$ & $0.80 \pm 0.54$ & 0.85 & $0.10-1.40$ & 0.1250 \\
\hline 20 & 4 & $10.66 \pm 1.40$ & 10.78 & $8.85-12.25$ & $9.74 \pm 0.93$ & 9.65 & $8.70-10.95$ & $0.92 \pm 0.57$ & 1.07 & $0.15-1.40$ & 0.1250 \\
\hline 21 & 4 & $10.79 \pm 1.38$ & 10.95 & $8.95-12.30$ & $10.03 \pm 0.98$ & 10.05 & $8.80-11.20$ & $0.76 \pm 0.42$ & 0.90 & $0.15-1.10$ & 0.1250 \\
\hline 22 & 3 & $11.67 \pm 0.85$ & 11.25 & $11.10-12.65$ & $10.60 \pm 0.65$ & 10.30 & $10.15-11.35$ & $1.07 \pm 0.20$ & 0.95 & $0.95-1.30$ & 0.2500 \\
\hline 23 & 3 & $12.05 \pm 0.88$ & 12.00 & $11.20-12.95$ & $10.87 \pm 0.75$ & 10.65 & $10.25-11.70$ & $1.18 \pm 0.21$ & 1.25 & $0.95-1.35$ & 0.2500 \\
\hline 24 & 3 & $12.13 \pm 0.98$ & 12.05 & $11.20-13.15$ & $11.03 \pm 0.94$ & 10.85 & $10.20-12.05$ & $1.10 \pm 0.10$ & 1.10 & $1.00-1.20$ & 0.2500 \\
\hline 25 & 4 & $12.25 \pm 0.86$ & 12.30 & $11.15-13.25$ & $10.99 \pm 0.85$ & 10.85 & $10.10-12.15$ & $1.26 \pm 0.22$ & 1.28 & $1.05-1.45$ & 0.1250 \\
\hline
\end{tabular}

*Statistically significant. 
$10.99 \pm 0.85 \mathrm{~mm}$, respectively, both of which were not a statistically significant reduction in size from the baseline $(\mathrm{P}=0.125)$.

Next, we analyzed our data to see if there was any differential effect of the toxin injection on the muscle with (clenching phase) or without (resting phase) contraction (Table 3, Fig. 2 and 3). The difference between the size of the muscle at the clenching and resting phases was statistically significant up to the first 2 weeks. From weeks 3 to 5 , this difference was no longer apparent but became statistically significant again from weeks 6 through 15 . This change in significance from weeks 3 to 5 may indicate that the toxin has a greater effect on the clenching phase compared to the resting phase. The statistical significance of the difference between the clenching and resting phase was lost again from weeks 16 through 25, but this may have been due to the smaller sample size for these 10 weeks.

The peak of the size reduction occurred at week 11 with a 4.68 $\pm 1.06 \mathrm{~mm}$ reduction for the clenching phase and a $3.23 \pm 0.47 \mathrm{~mm}$ reduction for the resting phase, representing a reduction of $31.1 \%$ and $25.8 \%$ from the baseline, respectively (Table 4 ). Although there was gradual muscle size recovery over the study period after week 11 , there was a discernable reduction of $4.34 \pm 1.31 \mathrm{~mm}$ for the
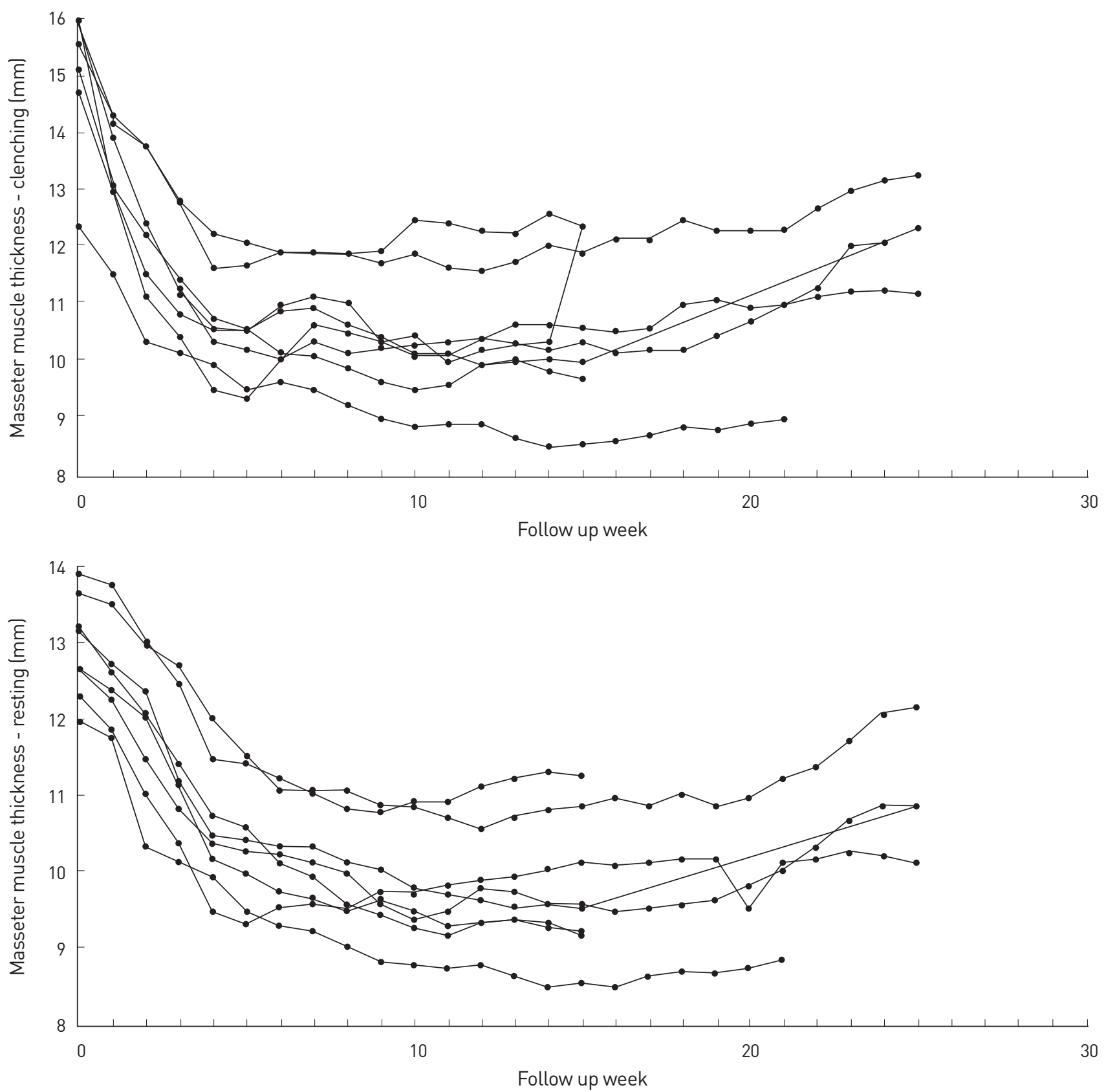

Fig. 2. Masseter muscle thickness at each visit by subject. 


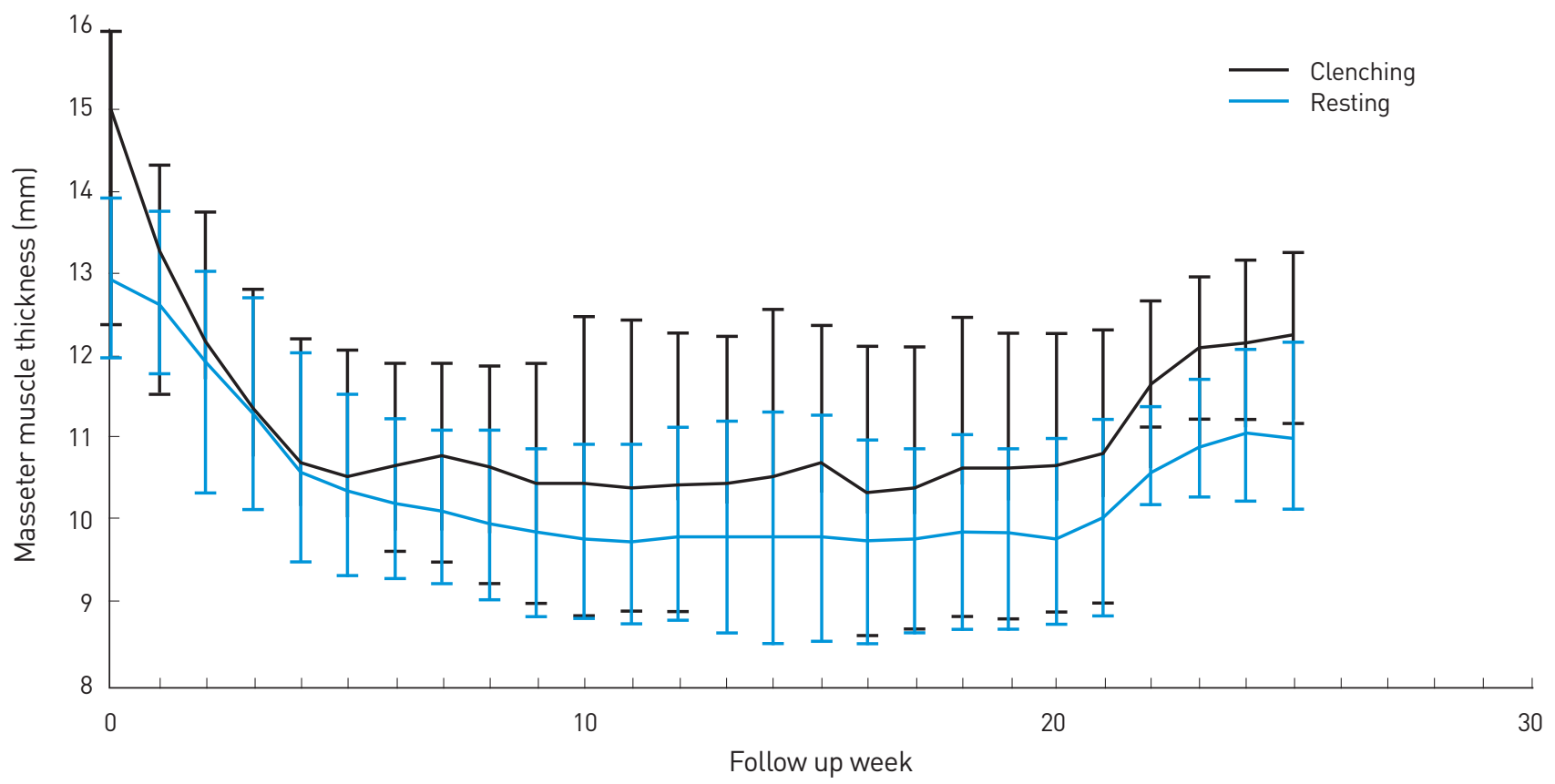

Fig. 3. Masseter muscle thickness at each visit.

clenching phase and $3.17 \pm 0.62 \mathrm{~mm}$ for the resting phase at week 15 (28.8\% and $24.6 \%$ reduction, respectively); and $3.08 \pm 0.64 \mathrm{~mm}$ for the clenching phase and $2.01 \pm 0.28 \mathrm{~mm}$ for the resting phase at week 25 (20.1\% and $15.6 \%$ reduction, respectively).

Lastly, the weekly change in muscle size for both the clenching and resting phases was analyzed (Table 5). For the clenching phase, size reduction occurred up to week 11 with the greatest reduction occurring 1 week after injection $(1.79 \pm 0.63 \mathrm{~mm}$, representing an $11.8 \%$ reduction). Gradual muscle size recovery occurred after week 11. For the resting phase, size reduction occurred up to week 21 with the greatest reduction occurring between weeks 1 and 2 $(0.71 \pm 0.36 \mathrm{~mm}$, representing a $5.7 \%$ reduction). There was gradual recovery in muscle size after week 21 but, as with the clenching phase, the masseter did not return to the baseline thickness.

\section{DISCUSSION}

There has been a homogenization of what defines beauty through globalization and the advent of global mass media. From an anthropometric standpoint, Asians often have a wider face and a more developed mandible [1]. The width of the lower face is determined by a combination of the mandibular bone, masseter muscle, and overlying subcutaneous fat tissue. For example, the average gap between the masticatory muscles of a Western women is from 105 to $109 \mathrm{~mm}$ whereas the average for a Korean women is from 117.80 to $125.25 \mathrm{~mm}$, showing that Korean women have a gap that is approximately 12 to $20 \mathrm{~mm}$ wider than Western women [5-9]. It is evident that the thickness of the masseter muscle can contribute greatly to the perception of a wide-angled face. This, however, is often viewed as an unaesthetic characteristic and has led to increasing attention to procedures aimed at attaining a narrower, more Westernized face. As such, much attention has turned to reduction of a square-angled mandible.

However, attempts to reduce the size of the lower face are not new. To achieve a slim and smooth contour line of the lower face, conventional treatment has concentrated on two approaches: surgical resection of the masseteric muscle or modeling ostectomy of the square-angled mandible [10-12]. Since Legg [13] first described bilateral masseteric hypertrophy as a benign condition characterized by bilateral enlargement of the masseter muscles in 1880, conservative treatments, including systemic medications, have been described. Gurney [14] in 1947 performed a masseteric resection through skin incision, and in 1951, Converse used the intraoral route to resect the masseteric muscle together with the bone $[3,4,14]$.

In 2001, von Lindern et al. [15] reported on the successful use of botulinum toxin A (Dysport) for treatment of masseteric hypertrophy. Since it was first used in 1976 for facial spasms, the use of botulinum toxin has expanded to treatment of a myriad of problems, including facial rhytids, a square-angled mandible, hyperhidrosis, and even migraines [16-19].

We published our initial report on the efficacy of botulinum toxin A for the treatment of masseter hypertrophy in 2005 [3]. This was followed by a long-term retrospective analysis in 2010 [4] where we showed the efficacy of the injections over a longer period of time. In addition, we showed that there is a positive correlation between the number of injections and the decrease in muscle size. 
Table 4. Change and percent change of masseter muscle thickness from baseline

\begin{tabular}{|c|c|c|c|c|c|c|c|c|}
\hline \multirow{3}{*}{ Week } & \multirow{3}{*}{ State } & \multirow{3}{*}{$\mathrm{N}$} & \multicolumn{6}{|c|}{ Masseter muscle thickness (mm) } \\
\hline & & & \multicolumn{3}{|c|}{ Change } & \multicolumn{3}{|c|}{ Percent change } \\
\hline & & & Mean \pm SD & Median & Min-Max & Mean \pm SD & Median & Min-Max \\
\hline \multirow[t]{2}{*}{1} & Clenching & 8 & $-1.79 \pm 0.63$ & -1.75 & $-3.00 \sim-0.84$ & $-11.77 \pm 3.65$ & -11.42 & $-18.81 \sim-6.80$ \\
\hline & Resting & 8 & $-0.34 \pm 0.16$ & -0.35 & $-0.60 \sim-0.15$ & $-2.63 \pm 1.27$ & -2.77 & $-4.55 \sim-1.08$ \\
\hline \multirow[t]{2}{*}{2} & Clenching & 8 & $-2.89 \pm 0.83$ & -3.03 & $-3.80 \sim-1.80$ & $-19.17 \pm 5.06$ & -19.63 & $-24.49 \sim-11.58$ \\
\hline & Resting & 8 & $-1.04 \pm 0.34$ & -1.02 & $-1.65 \sim-0.65$ & $-8.17 \pm 3.05$ & -7.59 & $-13.81 \sim-5.13$ \\
\hline \multirow[t]{2}{*}{3} & Clenching & 8 & $-3.70 \pm 0.92$ & -3.87 & $-4.80 \sim-2.25$ & $-24.47 \pm 5.24$ & -25.97 & $-30.09 \sim-17.68$ \\
\hline & Resting & 8 & $-1.67 \pm 0.35$ & -1.82 & $-2.00 \sim-0.95$ & $-13.06 \pm 3.07$ & -14.13 & $-15.85 \sim-6.96$ \\
\hline \multirow[t]{2}{*}{4} & Clenching & 8 & $-4.38 \pm 0.99$ & -4.50 & $-5.40 \sim-2.45$ & $-28.95 \pm 5.53$ & -30.20 & $-35.71 \sim-19.84$ \\
\hline & Resting & 8 & $-2.37 \pm 0.38$ & -2.47 & $-2.85 \sim-1.65$ & $-18.43 \pm 3.20$ & -18.56 & $-23.17 \sim-12.09$ \\
\hline \multirow[t]{2}{*}{5} & Clenching & 8 & $-4.51 \pm 0.91$ & -4.58 & $-5.45 \sim-2.90$ & $-29.90 \pm 5.02$ & -30.71 & $-36.73 \sim-23.48$ \\
\hline & Resting & 8 & $-2.58 \pm 0.25$ & -2.58 & $-3.00 \sim-2.15$ & $-20.04 \pm 2.56$ & -20.49 & $-24.39 \sim-15.75$ \\
\hline \multirow[t]{2}{*}{6} & Clenching & 8 & $-4.37 \pm 0.94$ & -4.43 & $-5.85 \sim-2.75$ & $-28.94 \pm 4.99$ & -29.73 & $-36.68 \sim-22.27$ \\
\hline & Resting & 8 & $-2.77 \pm 0.20$ & -2.75 & $-3.10 \sim-2.45$ & $-21.46 \pm 1.89$ & -22.13 & $-23.48 \sim-19.05$ \\
\hline \multirow[t]{2}{*}{7} & Clenching & 8 & $-4.26 \pm 0.90$ & -4.08 & $-5.90 \sim-2.90$ & $-28.20 \pm 4.55$ & -27.19 & $-36.99 \sim-23.48$ \\
\hline & Resting & 8 & $-2.84 \pm 0.24$ & -2.80 & $-3.30 \sim-2.55$ & $-22.03 \pm 2.00$ & -22.02 & $-25.00 \sim-19.05$ \\
\hline \multirow[t]{2}{*}{8} & Clenching & 8 & $-4.42 \pm 0.93$ & -4.18 & $-6.10 \sim-3.15$ & $-29.27 \pm 4.85$ & -28.03 & $-38.24 \sim-23.79$ \\
\hline & Resting & 8 & $-3.01 \pm 0.30$ & -2.90 & $-3.65 \sim-2.70$ & $-23.29 \pm 2.47$ & -22.98 & $-27.65 \sim-20.50$ \\
\hline \multirow[t]{2}{*}{9} & Clenching & 8 & $-4.61 \pm 0.95$ & -4.45 & $-6.35 \sim-3.40$ & $-30.58 \pm 5.00$ & -30.27 & $-39.81 \sim-24.76$ \\
\hline & Resting & 8 & $-3.10 \pm 0.34$ & -3.07 & $-3.80 \sim-2.60$ & $-24.01 \pm 2.64$ & -24.03 & $-28.79 \sim-21.14$ \\
\hline \multirow[t]{2}{*}{10} & Clenching & 8 & $-4.61 \pm 1.11$ & -4.38 & $-6.50 \sim-3.50$ & $-30.61 \pm 6.26$ & -29.76 & $-40.75 \sim-21.94$ \\
\hline & Resting & 8 & $-3.18 \pm 0.41$ & -3.20 & $-3.95 \sim-2.60$ & $-24.65 \pm 3.30$ & -25.58 & $-29.92 \sim-20.15$ \\
\hline \multirow[t]{2}{*}{11} & Clenching & 8 & $-4.68 \pm 1.06$ & -4.58 & $-6.40 \sim-3.50$ & $-31.06 \pm 5.87$ & -31.12 & $-40.13 \sim-22.26$ \\
\hline & Resting & 8 & $-3.23 \pm 0.47$ & -3.23 & $-4.05 \sim-2.50$ & $-24.97 \pm 3.62$ & -25.77 & $-30.68 \sim-20.15$ \\
\hline \multirow[t]{2}{*}{12} & Clenching & 8 & $-4.62 \pm 0.98$ & -4.45 & $-6.05 \sim-3.50$ & $-30.64 \pm 5.25$ & -30.27 & $-37.93 \sim-23.20$ \\
\hline & Resting & 8 & $-3.16 \pm 0.50$ & -3.27 & $-3.90 \sim-2.45$ & $-24.43 \pm 3.75$ & -25.29 & $-29.55 \sim-18.68$ \\
\hline 13 & Clenching & 8 & $-4.58 \pm 0.93$ & -4.28 & $-6.00 \sim-3.75$ & $-30.44 \pm 5.17$ & -30.32 & $-37.62 \sim-23.51$ \\
\hline & Resting & 8 & $-3.14 \pm 0.52$ & -3.25 & $-3.85 \sim-2.40$ & $-24.36 \pm 4.12$ & -24.70 & $-29.17 \sim-17.95$ \\
\hline 14 & Clenching & 8 & $-4.55 \pm 1.05$ & -4.25 & $-6.15 \sim-3.40$ & $-30.27 \pm 6.18$ & -30.76 & $-38.56 \sim-21.32$ \\
\hline & Resting & 8 & $-3.16 \pm 0.58$ & -3.22 & $-3.95 \sim-2.30$ & $-24.47 \pm 4.72$ & -25.49 & $-29.92 \sim-17.22$ \\
\hline 15 & Clenching & 8 & $-4.34 \pm 1.31$ & -4.00 & $-6.30 \sim-2.35$ & $-28.83 \pm 7.88$ & -29.70 & $-39.50 \sim-15.99$ \\
\hline & Resting & 8 & $-3.17 \pm 0.62$ & -3.27 & $-4.00 \sim-2.20$ & $-24.56 \pm 4.95$ & -26.09 & $-30.30 \sim-17.58$ \\
\hline 16 & Clenching & 4 & $-4.11 \pm 0.67$ & -4.00 & $-5.00 \sim-3.45$ & $-28.66 \pm 4.70$ & -29.67 & $-33.11 \sim-22.19$ \\
\hline & Resting & 4 & $-2.98 \pm 0.53$ & -3.08 & $-3.50 \sim-2.25$ & $-23.53 \pm 4.80$ & -23.26 & $-29.29 \sim-18.29$ \\
\hline 17 & Clenching & 4 & $-4.06 \pm 0.66$ & -3.92 & $-4.95 \sim-3.45$ & $-28.29 \pm 4.48$ & -29.10 & $-32.78 \sim-22.19$ \\
\hline & Resting & 4 & $-2.94 \pm 0.51$ & -3.10 & $-3.35 \sim-2.20$ & $-23.19 \pm 4.32$ & -23.42 & $-28.03 \sim-17.89$ \\
\hline 18 & Clenching & 4 & $-3.84 \pm 0.79$ & -3.65 & $-4.95 \sim-3.10$ & $-26.74 \pm 5.43$ & -27.13 & $-32.78 \sim-19.94$ \\
\hline & Resting & 4 & $-2.86 \pm 0.50$ & -3.00 & $-3.30 \sim-2.15$ & $-22.62 \pm 4.40$ & -22.68 & $-27.62 \sim-17.48$ \\
\hline 19 & Clenching & 4 & $-3.81 \pm 0.61$ & -3.62 & $-4.70 \sim-3.30$ & $-26.58 \pm 4.44$ & -26.99 & $-31.13 \sim-21.22$ \\
\hline & Resting & 4 & $-2.89 \pm 0.51$ & -3.05 & $-3.30 \sim-2.15$ & $-22.79 \pm 4.24$ & -23.03 & $-27.62 \sim-17.48$ \\
\hline 20 & Clenching & 4 & $-3.76 \pm 0.50$ & -3.65 & $-4.45 \sim-3.30$ & $-26.22 \pm 3.66$ & -27.10 & $-29.47 \sim-21.22$ \\
\hline & Resting & 4 & $-2.96 \pm 0.20$ & -2.90 & $-3.25 \sim-2.80$ & $-23.43 \pm 2.60$ & -22.65 & $-27.20 \sim-21.22$ \\
\hline 21 & Clenching & 4 & $-3.64 \pm 0.40$ & -3.58 & $-4.15 \sim-3.25$ & $-25.36 \pm 3.12$ & -26.50 & $-27.53 \sim-20.90$ \\
\hline & Resting & 4 & $-2.68 \pm 0.39$ & -2.67 & $-3.15 \sim-2.20$ & $-21.15 \pm 3.69$ & -20.19 & $-26.36 \sim-17.89$ \\
\hline 22 & Clenching & 3 & $-3.45 \pm 0.49$ & -3.60 & $-3.85 \sim-2.90$ & $-22.88 \pm 3.70$ & -24.49 & $-25.50 \sim-18.65$ \\
\hline & Resting & 3 & $-2.35 \pm 0.20$ & -2.35 & $-2.55 \sim-2.15$ & $-18.13 \pm 0.58$ & -18.35 & $-18.58 \sim-17.48$ \\
\hline 23 & Clenching & 3 & $-3.07 \pm 0.45$ & -3.10 & $-3.50 \sim-2.60$ & $-20.35 \pm 3.55$ & -20.53 & $-23.81 \sim-16.72$ \\
\hline & Resting & 3 & $-2.08 \pm 0.10$ & -2.05 & $-2.20 \sim-2.00$ & $-16.10 \pm 0.49$ & -15.83 & $-16.67 \sim-15.81$ \\
\hline 24 & Clenching & 3 & $-2.98 \pm 0.55$ & -3.05 & $-3.50 \sim-2.40$ & $-19.81 \pm 4.20$ & -20.20 & $-23.81 \sim-15.43$ \\
\hline & Resting & 3 & $-1.92 \pm 0.16$ & -1.85 & $-2.10 \sim-1.80$ & $-14.87 \pm 1.96$ & -14.23 & $-17.07 \sim-13.31$ \\
\hline 25 & Clenching & 4 & $-3.08 \pm 0.64$ & -3.18 & $-3.65 \sim-2.30$ & $-20.09 \pm 4.27$ & -20.71 & $-24.15 \sim-14.79$ \\
\hline & Resting & 4 & $-2.01 \pm 0.28$ & -2.00 & $-2.30 \sim-1.75$ & $-15.55 \pm 2.56$ & -15.86 & $-17.89 \sim-12.59$ \\
\hline
\end{tabular}


Table 5. Change and percent change of masseter muscle thickness from a week ago

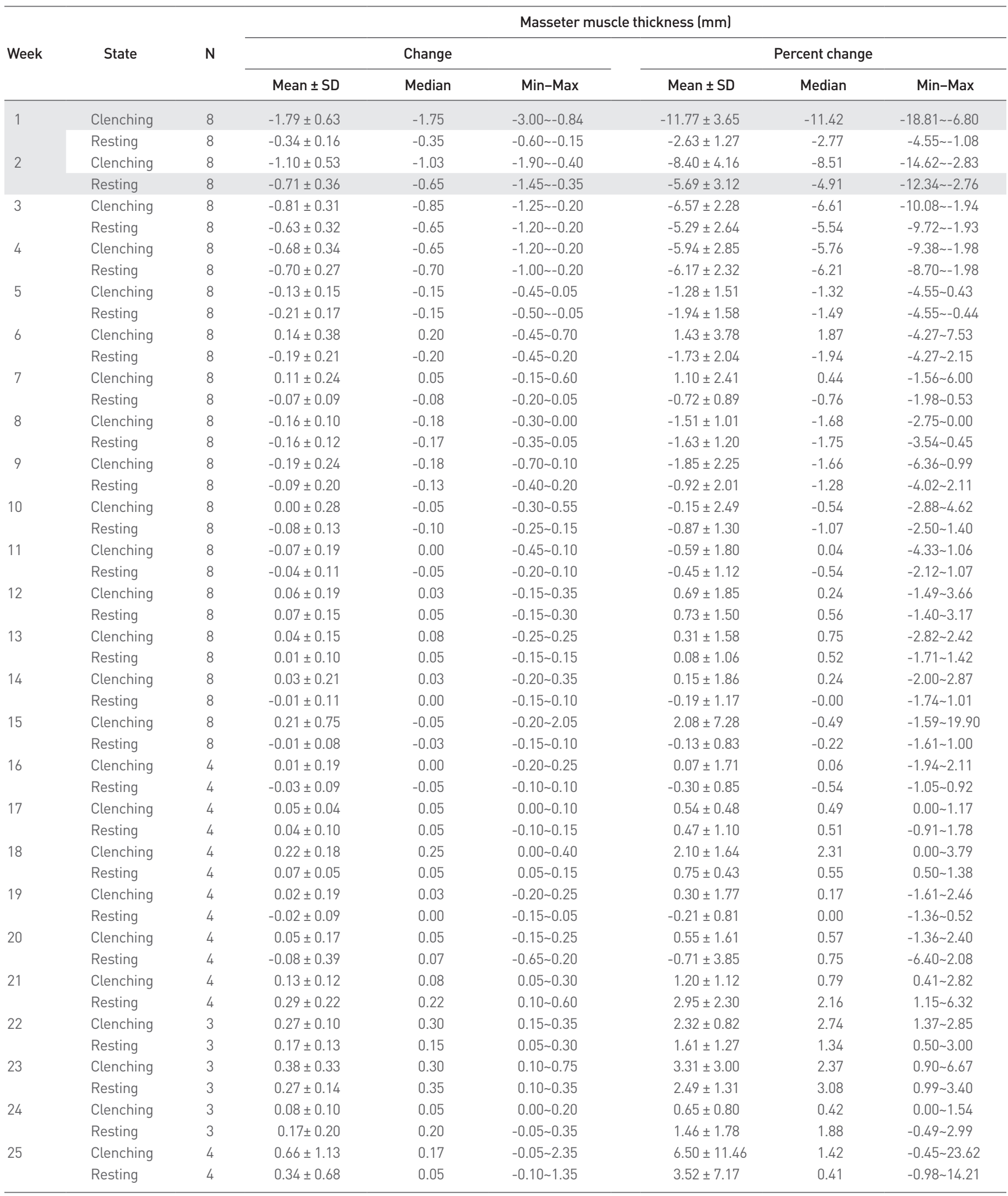


The purpose of the current study was to evaluate the thickness of the masseter muscle at weekly intervals to determine the physiologic effects of injection, for both the resting and clenching phases.

In summary, the following conclusions can be drawn from the data presented:

1) Clenching strength is the first to be affected by botulinum toxin $\mathrm{A}$ injection, leading to a differentially greater reduction in muscle thickness during the clenching phase compared to the resting phase during the first week.

2) For the resting phase, the greatest size reduction occurs at week 2.

3) The greatest reduction from baseline occurs at week 11 for both the clenching and resting phases.

4) For both phases, but especially for the clenching phase, there is gradual size recovery after week 11 , but the increase is not significant up to week 21 .

5) Although there was a statistically significant reduction in the thickness of the muscle at a 15-week follow-up, this significance was lost at a 25-week follow-up. This may be attributed to our sample size as only 4 out of the 8 patients were followed up to 25 weeks. However, there was still a gross reduction in muscle thickness at 25 weeks after treatment, attesting to the longevity of the effects of botulin toxin A on the treatment of masseteric hypertrophy.

A confounding variable is that three of our patients required an additional injection at a 2-week follow-up visit for residual muscle activity. We have previously reported, however, on the benefits of such booster injections for overall treatment success in a select group of patients [1,3,4]. Moreover, a booster injection at a 2-week followup visit is routinely performed for botulinum toxin $\mathrm{A}$ injection for facial rejuvenation. Given the results of our study, re-injection at 4 weeks may be better for maximizing the physiologic response of the muscle to the toxin.

One of the limitations of this study is the small sample size. A larger sample size may have given us a more statistically significant reduction in size over a longer period of time. However, the patients were selected at random and all of our patients individually displayed similar trends in reduction of muscle size during the same treatment intervals.

\section{CONCLUSION}

Botulinum toxin A injection was found to objectively reduce masseteric hypertrophy with a differential effect on the clenching versus resting phases in our small sample. It would be worth investigating this modality for the treatment of a square-angled mandible in a clinical trial in the future.

\section{PATIENT CONSENT}

Patients provided written consent for the use of their images.

\section{REFERENCES}

1. Kim NH, Ahn TJ, Park RH, et al. Botulinum toxin type A injections for facial contouring. In: Pu LLQ, editor. Aesthetic plastic surgery in Asians: principles and techniques. Boca Raton, FL: CRC Press; 2015. p.171-82.

2. Smyth AG. Botulinum toxin treatment of bilateral masseteric hypertrophy. Br J Oral Maxillofac Surg 1994;32:29-33.

3. Kim NH, Chung JH, Park RH, et al. The use of botulinum toxin type A in aesthetic mandibular contouring. Plast Reconstr Surg 2005;115: 919-30.

4. Kim NH, Park RH, Park JB. Botulinum toxin type A for the treatment of hypertrophy of the masseter muscle. Plast Reconstr Surg 2010;125: 1693-705.

5. Whitaker LA. Aesthetic contouring of the facial support system. Clin Plast Surg 1989;16:815-23.

6. Lee Y, Han K, Kang J. Korean standards of craniomaxillofacial skeleton. J Korean Soc Plast Reconstr Surg 1994;21:438-51.

7. Kim CJ, Ham KS, Kim Y, et al. A facial anthropometric study on the Korean youths. J Korean Soc Plast Reconstr Surg 1988;15:427-36.

8. Park JS, Ham KS, Cho YJ. An anthropometric study on the young Korean faces related to their facial impression. J Korean Soc Plast Reconstr Surg 1989;16:920-5.

9. Cho J, Han K, Kang J. Normal anthropometric values and standardized templates of Korean face ad head. J Korean Soc Plast Reconstr Surg 1993;20:995-1005.

10. Baek SM, Kim SS, Bindiger A. The prominent mandibular angle: preoperative management, operative technique, and results in 42 patients. Plast Reconstr Surg 1989;83:272-80.

11. Baek SM. Aesthetic contouring of the facial skeleton. Probl Plast Reconstr Surg 1991;1:667-82.

12. Yang DB, Park CG. Mandibular contouring surgery for purely aesthetic reasons. Aesthetic Plast Surg 1991;15:53-60.

13. Legg JW. Enlargement of the temporal and masseter muscles on both sides. Trans Pathol Soc Lond 1880;31:361-6.

14. Gurney CE. Chronic bilateral benign hypertrophy of the masseter muscles. Am J Surg 1947;73:137-9.

15. von Lindern JJ, Niederhagen B, Appel T, et al. Type A botulinum toxin for the treatment of hypertrophy of the masseter and temporal muscles: an alternative treatment. Plast Reconstr Surg 2001;107:327-32.

16. Carruthers A, Carruthers J. History of the cosmetic use of Botulinum A exotoxin. Dermatol Surg 1998;24:1168-70.

17. Park MY, Ahn KY, Jung DS. Botulinum toxin type A treatment for contouring of the lower face. Dermatol Surg 2003;29:477-83; discussion 83.

18. Heckmann M, Ceballos-Baumann AO, Plewig G. Botulinum toxin A for axillary hyperhidrosis (excessive sweating). N Engl J Med 2001;344: 488-93.

19. Rohrich RJ, Janis JE, Fagien S, et al. The cosmetic use of botulinum toxin. Plast Reconstr Surg 2003;112:177S-88S; quiz 88S, 92S; discussion 89 S-91S. 